\title{
ASSESSMENTS OF EU COUNTRIES FOR INDIVIDUALS TRADING POSSIBILITIES
}

\author{
Juozas MERKEVIČIUS*, Chitra SINGH DESWAL \\ Department of Business Technologies and Entrepreneurship, Faculty of Business Management, \\ Vilnius Gediminas Technical University, Sauletekio al. 11, LT-10223, Vilnius, Lithuania \\ ${ }^{*}$ E-mail: juozas.merkevicius@vgtu.lt
}

\begin{abstract}
Data and correspondences innovation (ICT) is an extensional term for data innovation (IT) that burdens the job of brought together interchanges and the reconciliation of media communications (phone lines and remote signs) and PCs, just as essential endeavor programming, middleware, stockpiling, and varying media frameworks, that empower clients to get to, store, transmit, and control data. At the most basic level, ICT encompasses all technologies that allow individuals and businesses to interact in the digital world. It is like Information Technology (IT), yet centers fundamentally around correspondence innovations. This incorporates the Internet, remote systems, mobile phones, and other correspondence mediums. There are many problems faced during International trade which can be solved by using virtual organizations for international trades. Because of globalization, numerous organizations are presently working in more than one nation which brings forth multicultural association where representatives from more than one nation are cooperating. This paper aim of the study to find the best country for international trade using virtual organization which was accompalished using Topsis method. The following European countries (Germany, Finland, Check Republic, Austria, Estonia, Denmark, France and Belgium) were analysed during years 2014 to 2018. The limitation faced was that the data for all European countries was not available.
\end{abstract}

Keywords: information technologies, information communication technologies, international trade, virtual organizations, multicultural, Topsis.

\section{Introduction}

Regardless of the reality that the world is progressing as far as information technology, creative and prevalent strategies for arranging advertising endeavors (like even association, organize association, virtual association), worldwide endeavors for smooth global exchanges, etc, yet universal showcasing isn't that much simple to seek after, it has become a test to acknowledge. Following are some of the problems faced during International trade: Tariff Bariers, Administrative Policies, Considerable Diversities, Political Instability or Environment, lace Constraints (Diverse Geography), Variation in Exchange Rates, Norms and Ethical Challenges, Terrorism and Racism. These mentioned problems can be solved by using virtual organizations for international trades. Because of globalization, numerous organizations are currently working in more than one nation. This crossing point of land restricts by the associations gives the presentation of multicultural association where agents from more than one country are coordinating. The facts may confirm that organizations are finding these developments as appealing and worthwhile yet working and dealing with a worldwide business is ordinarily significantly harder than dealing with a neighborhood organization. The principle purpose behind the extension of organizations is to make worldwide seriousness by lessening creation costs and misusing market openings offered by profession progression and financial reconciliation. Viable information and utilization of culturally diverse decent variety can give a wellspring of experience and imaginative deduction to improve the serious situation of organizations. Notwithstanding, social contrasts can meddle with the effective fruition of organizational objectives in the present multicultural worldwide business network. To maintain a strategic distance from social false impressions, supervisors should be socially delicate and advance inventiveness and inspiration through adaptable administration. For virtual business, online correspondence between two organization is significant for which Internet association is fundamental.

Trading with country having high range of Internet facilities will result in huge number of organization options for business. The paper provides the data and analysis for Inetrnet usage by EU countries (Germany, Finland, Check Republic, Austria, Estonia, Denmark, France and Belgium) to find the best country for trade. The 
limitations of the work includes: Limited access to data, Time constraints and Conflicts arising from cultural bias and other personal issues. Aim of the research: To analyse ICT access and usage by Individulas data for different EU countries and to find the best country to trade with. Research Tasks: 1) To collect the data of Internet usuage by Individuals in 8 different EU countries; 2) Analyse the data using one of the MCDM method; 3) Rank the countries according to calculated results; 4) Find the best country to trade with. Methods used: summarization, comparison, processing of statistical data, there was used TOPSIS, MCDM method to reach conclusion.

\section{Theoretical background}

Securing the best job placement is the test, in light of the fact that among numerous potential placements, it is required to discover one that gives a satisfactory exchange off among execution and personal creative force utilization. The authors Blagodurov, Fedorova, and Evgeny (2015) propose to handle the issue via multi-objective optimization. Thy provide the solution how to taking into account differnet obejctives that have different sides, to finde appopriate job place. Chen, Chen, and Faulkner (2005) is thinking that an enterprise level information system should be created using advanced methods of paning and design of the system. The authors proposes a set of conceptual models that incloude different design guidelines and help to create an apporiate structure for the effective intelligent system. They presented an example of the trade center, and how the objective was achived using a computerised control of all systems of enterprise, that gratly increased capabilities of decision-making. The author Gabriel (2003) analyses global issues of law in field of electronic commerce and propose for UN Commission to make some changes in field of International Trade Law. Husby (1984) analysis issues of entering foreign markets with the objective of increasing U.S. companies revenues.

Debenham and Simoff (2009) described the elements that build the believability of electronic marketplaces and made analysis of the different technologies that support this process. As per creators the development of the electronic commercial centers is an inborn piece of the advancement of the Web, especialy this posilbility increased using Web 3.0 technology. Virtual conditions and web based games are turning into a significant market power. Simultaneously, the virtual property contained in these environments is being traded for real money and thus attains a real value. The authors Cikic, Grottke, Lehmann-Grube, and Sablatnig (2008) talks about the main aspects and requirements of how virtual environments need to be built to face the new challenges of security and control. Alongside more prominent security, this will also reduce the cost of support, which is one of the major cost factors for online games. The authors Mattos, Ferraz, Costa, and Duarte (2012) have evaluated the performance of three virtualization tools OpenVZ, VMware and Xen, in case of their use for router virtualization. Apostolov (2008) introduces the concept of single window for exportimport clearance as an instrument for good governance. Through brought together documenting of exchange information by government organizations, the single window expands straightforwardness and lessens debasement, wastefulness and out of line rehearses in remote exchange. Web (applications) are customized utilizing HTML5, CSS, and JavaScript, and are circulated in the source code position. Oh, Kwon, Park, and Moon (2015) proposes such a movement system for web applications where we can spare the present condition of a running application and resume its execution on an alternate gadget by reestablishing the spared state. The authors Menon, Schubert, and Zwaenepoel (2009) have presented TwinDrivers, a framework which allows us to create safe and efficient hypervisor drivers from guest OS drivers. The O'Leary (1998) presented reviews of some virtual organizations and the costs and benefits of being in a virtual organization.

Luo, MacEachren, and Zwaenepoel (2011) present the GeoSocialApp that supports investigation of spatial interpersonal organizations among numerous spaces: network, attribute and geographical space. It likewise bolsters the investigation of network attributes from individual-level to community-level. The authors Parra and Wen (2014) have displayed aftereffects of research planned for anticipating web based exchanging communications utilizing highlights from the exchanging system also online interpersonal organization information. Utilizing a genuine ebusiness situation (Bill of Lading) the authors, Gordijn and Tan (2004) demonstrated that evalue, with certain augmentations, is equipped for displaying a control point of view that catches components for preventive and investigator controls. Also, they demonstrated that such controls themselves can be viewed as a sort of commercial services. Blumenstock (2005) presents a novel technique for estimating and assessing the social ties between countries. He displays a starter examination of the exact properties of this measurement utilizing a log of all global telephone calls to and from Rwanda. He found that examples of universal active and approaching calls intently equal examples of global fares and imports. Liu (2005), first introduces the background of ET application, then depicts the actual situation of ET development in Hong Kong China as an example, and analysis the impact of Electronic Trading on market functioning, at last give a brief conclusion. The author Rashid (2010) provides an overview of algorithmic trading processes as well as investigates a platform that will provide a domain based service oriented architecture (SOA) in which users can invoke certain functions within the system as services. Computers are making more and more decisions for us, and increasingly so in areas that require human judgment. A natural question to ask is how we should be thinking about the role of computers in managing our money. Should we trust our money to a robot? In an era of big data and machines to make sense of it all, do machines have an inherent advantage over humans? There is a surge of interest in Artificial Intelligence for financial prediction. 
Should we pay attention? Or is this an area where human judgment and input is always essential? The author Dhar (2015) provides theory which answers to these questions.

Daily, Loveland, and Steiner (1997) analysed culturally homogeneous groups of people and multicultural groups, the analysis showed that multicultural groups are mo effective in using ICT for decision making. The authors Clausen, Zolner, Soderberg, and Worm (2009) analysed issues of cultural intelligence and found that multicultural groups are more effective comparint to the homogeneous. The authors Lisak and Erez (2009) examines the role of leadership in multicultural groups and how it effects on team communication, team identity and team effectiveness. Powell, Piccoli, and Ives (2004) provides a review of previously published work and reports on the findings from early virtual team research in an effort to take stock of the current state of the art. Building on this review authors critically evaluated virtual team research and develop research questions that can guide future inquiry in this fertile area of inquiry. The author Robert (2013) analysed problem of leadership in virtual teams and proposed solutions how to incresase effectiveness of team performance. The authors Redmiles, Prikladnicki, Marczak, and Calefato (2013) analysed issue of trust in virtual teams and proposed methods how to increase it taking into account, that people of team are dispersed geographically.

Fischlmayr (2012) introduces the online business simulation VIBu RealGame ${ }^{\mathrm{TM}}$, which helps to overcome cultural differences as well as to acquire skills required for virtual multicultural teamwork. The authors Noll, Beecham, and Richardson (2011) have present a review of the global software development literature where they highlighted collaboration problems experienced by a cross-section of organizations in twenty-six studies. They also looked at the literature to answer how organizations are overcoming these barriers in practice. The authors Faltaous, Elbolock, and Talaat (2018) investigated different research probes using interactive Virtual Reality (VR) applications to increase such awareness. VR environments provide a high sense of immersion, which enhance the user's experience. In this work, they presented three VR interactive research probes that allow users to understand cultural differences and to reduce cultural misconceptions. The authors Massey, Hung, and Ramesh (2011) have explored how cultural tendencies, specifically country-of-origin differences relate to communication styles and how these may influence perceptions of task-technology fit by members of global virtual teams. The authors Y. Li, $\mathrm{H}$. Li, and Madche (2012) develops a theoretical model based on the extended adaptive structuration theory (EAST) and verify the model in a cross-border experiment. The result suggests that focal members' behavioral cultural intelligence strongly influences their remote partners' receptivity/trust. The authors Lewis, Ellis, and Kellogg (2010) reports an exploratory investigation where recently framed cross-national groups take part in an agreeable game in which one colleague has a position of authority. They depicted practices watched enhanced by overview and meeting information as far as initiative, peace making, social errors, and attention to assorted variety. They recommend that helpful exercises under time tension in a „low stakes“ virtual condition may invigorate dialog that can cultivate more prominent understanding and viable interac-tion in certifiable joint efforts.

\section{Evaluation of ICT access and usage by Individuals comparision in EU countries}

For assessment of Internet access and utilization by Individuals in ICT (see Table 1) was utilized multiple-criteria decision-making and multiple-criteria decision analysis. MCDM or MCDA are prominent condensing for numerous criteria basic leadership and various criteria choice investigation. MCDM is stressed over sorting out and handling decision and orchestrating issues including numerous criteria. The explanation behind existing is to help chiefs going up against such issues novel perfect response for such issues and it is essential to use leader's tendencies to isolate between courses of action. For this assessment was utlized The Technique for Order of Preference by Similarity to Ideal Solution TOPSIS method.

Table 1. Individuals using Internet - last $12 \mathrm{~m}(\%)(\mathrm{OECD}, 2019)$

\begin{tabular}{|l|l|l|l|l|l|}
\hline Country/Year & 2014 & 2015 & 2016 & 2017 & 2018 \\
\hline AUSTRIA & 82.46 & 84.63 & 85.11 & 88.39 & 87.82 \\
\hline BELGIUM & 86.15 & 86.06 & 87.31 & 88.83 & 89.93 \\
\hline CHECK REPUBLIC & 81.11 & 82.59 & 83.35 & 85.38 & 87.21 \\
\hline DENMARK & 96.37 & 96.57 & 97.13 & 97.32 & 97.85 \\
\hline ESTONIA & 85.54 & 89.14 & 88.03 & 88.93 & 89.98 \\
\hline FINLAND & 93.16 & 92.86 & 94.86 & 93.94 & 94.66 \\
\hline FRANCE & 85.69 & 87.25 & 87.54 & 88.20 & 89.34 \\
\hline GERMANY & 87.69 & 88.83 & 90.85 & 91.40 & 93.40 \\
\hline
\end{tabular}

The numbers in the table demonstrates the percentage use of Inetrnet access and usuage by Individuals in EU countries for that specific year. In the all analysed countries Internet usage constatny grows except Austria, which has decline in Internet usage percentage in year 2018. 


\subsection{Formulas, equations and calculations}

For the calculations topsis method and the required formulas have been used. In the TOPSIS method we assume that the ratings of alternatives and weights are represented by numerical data and the problem is solved by a single decision maker. Complexity arises when there are more than one decision makers because the preferred solution must be agreed on by interest groups who usually have different goals.

The TOPSIS method for a single decision maker. The idea of classical TOPSIS procedure can be expressed in a series of following steps:

Step 1. Construct the decision matrix and determine the weight of criteria.

- Let Sij score of option i using criterion $\mathrm{j}$

$-w j$ weight for criterion $\mathrm{j}$

$-\mathrm{Si}$ score of option $\mathrm{i}$ is given as:

$$
S i=\Sigma w j S i j
$$

Step 2. Calculate the normalized decision matrix.

This step transforms various attribute dimensions into non-dimensional attributes, which allows comparisons across criteria.

- Normalize score or data as follows:

$$
r i j=x i j /(\square x 2 i j) 1 / 2 \text { for } i=1, \ldots, m ; j=1, \ldots, n .
$$

Step 3. Calculate the weighted normalized decision matrix.

- Assume we have a set of weights for each criteria wj for $\mathrm{j}=1, \ldots n$.

- Multiply each column of the normalized decision matrix by its associated weight.

- An element of the new matrix is:

$$
v i j=w j \text { rij. }
$$

Step 4. Determine the positive ideal and negative ideal solutions.

- Ideal solution.

$$
A^{*}=\left\{v 1^{*}, \ldots, v n^{*}\right\},
$$

where $v^{*}=\left\{\max (v i j)\right.$ if $j \in J$; $\min (v i j)$ if $\left.j \in J^{\prime}\right\}$

- Negative ideal solution.

$$
A^{\prime}=\left\{v 1^{\prime}, \ldots, v n^{\prime}\right\}
$$

where $v^{\prime}=\left\{\min (v i j)\right.$ if $j \in J$; $\max (v i j)$ if $\left.j \in J^{\prime}\right\}$

Step 5. Calculate the separation measures from the positive ideal solution

and the negative ideal solution.

- The separation from the ideal alternative is:

$$
S_{i}^{+}=\sqrt{\sum_{j=1}^{n}\left(v_{i j}-v_{i}^{+}\right)^{2}}, \quad i=1,2, \ldots, m .
$$

- Similarly, the separation from the negative ideal alternative is:

$$
S_{i}^{-}=\sqrt{\sum_{j=1}^{n}\left(v_{i j}-v_{i}^{-}\right)^{2}}, i=1,2, \ldots, m .
$$

Step 6. Calculate the relative closeness to the positive ideal solution.

$$
C_{i}=\frac{S_{i}^{-}}{S_{i}^{-}+S_{i}^{+}} .
$$

Step 7. Rank the preference order or select the alternative closest to 1 .

In Step 1 is constructed decision matrix and determined the weight of criteria, results presented in Table 2. 
Table 2. Results after applying the step 1 of TOPSIS method (designed by authors)

\begin{tabular}{|l|c|c|c|c|c|}
\hline \multicolumn{1}{|c|}{ WEIGHT } & 0.2 & 0.2 & 0.2 & 0.2 & 0.2 \\
\hline Country/Year & 2014 & 2015 & 2016 & 2017 & 2018 \\
\hline AUSTRIA & 82.46 & 84.63 & 85.11 & 88.39 & 87.82 \\
\hline BELGIUM & 86.15 & 86.06 & 87.31 & 88.83 & 89.93 \\
\hline CHECK REPUBLIC & 81.11 & 82.59 & 83.35 & 85.38 & 87.21 \\
\hline DENMARK & 96.37 & 96.57 & 97.13 & 97.32 & 97.85 \\
\hline ESTONIA & 85.54 & 89.14 & 88.03 & 88.93 & 89.98 \\
\hline FINLAND & 93.16 & 92.86 & 94.86 & 93.94 & 94.66 \\
\hline FRANCE & 85.69 & 87.25 & 87.54 & 88.20 & 89.34 \\
\hline GERMANY & 87.69 & 88.83 & 90.85 & 91.40 & 93.40 \\
\hline
\end{tabular}

In Table 2 it was given an equal weightage to every country as the total weight should be 1 . So here weight for every country is 0.2 .

Step 2, calculated the normalized decision matrix and results presented in Table 3.

Table 3. Results after applying the step 2 of TOPSIS method (designed by authors)

\begin{tabular}{|l|c|c|c|c|c|}
\hline \multicolumn{1}{|c|}{ WEIGHT } & 0.2 & 0.2 & 0.2 & 0.2 & 0.2 \\
\hline Country/ Year & 2014 & 2015 & 2016 & 2017 & 2018 \\
\hline AUSTRIA & 27.5049 & 28.5832 & 13.7803 & 30.5666 & 29.8529 \\
\hline BELGIUM & 30.0216 & 29.5573 & 31.1090 & 30.8716 & 31.3047 \\
\hline CHECK REPUBLIC & 26.6117 & 27.2219 & 28.3511 & 28.5202 & 29.4397 \\
\hline DENMARK & 37.5671 & 37.2175 & 38.5004 & 37.0548 & 37.0614 \\
\hline ESTONIA & 29.5980 & 31.7109 & 31.6242 & 30.9412 & 31.3395 \\
\hline FINLAND & 35.1061 & 34.4128 & 36.7218 & 34.5256 & 34.6853 \\
\hline FRANCE & 29.7019 & 30.3804 & 31.2731 & 30.4353 & 30.8953 \\
\hline GERMANY & 31.1045 & 31.4907 & 33.6828 & 32.6838 & 33.7671 \\
\hline
\end{tabular}

In Table 3 was calculated normalized decision matrix, and presented results of each country from year 2014 to 2018.

Step 3, calculated the weighted normalized decision matrix, results presented in Table 4.

Table 4. Results after applying the step 3 of TOPSIS method (designed by authors)

\begin{tabular}{|l|c|c|c|c|c|}
\hline \multicolumn{1}{|c|}{ Country/Year } & 2014 & 2015 & 2016 & 2017 & 2018 \\
\hline AUSTRIA & 5.50 & 5.72 & 2.76 & 6.11 & 5.97 \\
\hline BELGIUM & 6.00 & 5.91 & 6.22 & 6.17 & 6.26 \\
\hline CHECK REPUBLIC & 5.32 & 5.44 & 5.67 & 5.70 & 5.89 \\
\hline DENMARK & 7.51 & 7.44 & 7.70 & 7.41 & 7.41 \\
\hline ESTONIA & 5.92 & 6.34 & 6.32 & 6.19 & 6.27 \\
\hline FINLAND & 7.02 & 6.88 & 7.34 & 6.91 & 6.94 \\
\hline FRANCE & 5.94 & 6.08 & 6.25 & 6.09 & 6.18 \\
\hline GERMANY & 6.22 & 6.30 & 6.74 & 6.54 & 6.75 \\
\hline Maximum & 7.51 & 7.44 & 7.70 & 7.41 & 7.41 \\
\hline Minimum & 5.32 & 5.44 & 5.67 & 5.70 & 5.89 \\
\hline
\end{tabular}

Table 4 presents numbers after calculating the weighted normalized decision matrix. Multiply the columns of normalized decision matrix by the associated weights from entropy method. The weighted and normalized decision matrix is obtained. Also Maximum and Minimum value in each coulumn has been calculated. 
Step 4, determined the positive ideal and negative ideal solutions, results presented in Table 5.

Table 5. Results after applying the step 4 of TOPSIS method (designed by authors)

\begin{tabular}{|c|c|c|c|c|c|c|c|c|}
\hline $\mathrm{V}+$ & 35.24 & 9.66 & 18.15 & 0.00 & 8.45 & 1.17 & 9.71 & 5.11 \\
\hline $\mathrm{V}-$ & 8.77 & 1.35 & 0.00 & 18.15 & 1.97 & 10.30 & 1.35 & 4.12 \\
\hline
\end{tabular}

In Table 5 presented the sum of values of countries for years 2014-2018 positive and negative ideal solutions.

Step 5, calculated the separation measures from the positive ideal solution and the negative ideal solution, results presented in Table 6.

Table 6. Results after applying the step 5 of TOPSIS method (designed by authors)

\begin{tabular}{|c|c|c|c|c|c|c|c|c|}
\hline S+ & 5.936116 & 3.108797 & 4.260856 & 0 & 2.906735 & 1.079504 & 3.115634 & 2.260335 \\
\hline S- & 2.961862 & 1.160965 & 0 & 4.260856 & 1.403612 & 3.209400 & 1.163625 & 2.028777 \\
\hline
\end{tabular}

In Table 6 it was calculated sparation measures from positive ideal solutions and negative ideal solutions the content of positive ideal and negative ideal, distances of each alternative from the ideal and nadir for our problem, and the relative closeness to the ideal solution.

Step 6 results presented in Table 7.

Table 7. Results after applying the step 6 of TOPSIS method (designed by authors)

\begin{tabular}{|c|c|c|c|c|c|c|c|c|}
\hline Countries & Austria & Belgium & $\begin{array}{c}\text { Check } \\
\text { Republic }\end{array}$ & Denamrk & Estonia & Finland & France & Germany \\
\hline Final Result & 0.33287 & 0.27190 & 0.00000 & 1.00000 & 0.32564 & 0.74830 & 0.27192 & 0.47301 \\
\hline
\end{tabular}

In Table 7, after calculations established relative closeness to the positive ideal solution.

Step 7, calculated the rank of the preference order results presented in Table 8.

Table 8: Results after applying the step 7 of TOPSIS method (designed by authors)

\begin{tabular}{|l|l|l|l|l|l|c|}
\hline \multicolumn{1}{|c|}{ Country/Year } & 2014 & 2015 & 2016 & 2017 & 2018 & Rank \\
\hline AUSTRIA & 82.46 & 84.63 & 85.11 & 88.39 & 87.82 & 4 \\
\hline BELGIUM & 86.15 & 86.06 & 87.31 & 88.83 & 89.93 & 7 \\
\hline CHECK REPUBLIC & 81.11 & 82.59 & 83.35 & 85.38 & 87.21 & 8 \\
\hline DENMARK & 96.37 & 96.57 & 97.13 & 97.32 & 97.85 & 1 \\
\hline ESTONIA & 85.54 & 89.14 & 88.03 & 88.93 & 89.98 & 5 \\
\hline FINLAND & 93.16 & 92.86 & 94.86 & 93.94 & 94.66 & 2 \\
\hline 6FRANCE & 85.69 & 87.25 & 87.54 & 88.20 & 89.34 & 6 \\
\hline G3ERMANY & 87.69 & 88.83 & 90.85 & 91.40 & 93.40 & 3 \\
\hline
\end{tabular}

Tabale 8 presents rank of each country according to Internet Access and usage by Individuals in eight EU countries mentioned. According to Results and Ranking, it can be found that Denmark is the best country to trade with and Check Republic is the worst one.

\section{Conclusions}

Information technology (IT) benefits the business world and it allows organizations to work more efficiently and to maximize productivity and so on. In business, mpeople look for ways to do more work in a shorter amount of time and it should be only possible through the development of Information Technology. There are many problems faced during International Trade. Literature Reviews provided in the paper concludes that to overcome these problems business can be done virtually through virtual organizations. There are some ways to deal with cultural differences in multicultural organizations. For an organization to work well, it's required to have good leader. The leader should be able to interact with the employees and make them to do work fastly and effectively, which would lead 
the organization to huge profit. Information and communication technologies (ITC) directly responsible for grow of virtual business. The paper provides the data for Inetrnet usage by Eu countries (Austria, Belgium, Check Republic, Denmark, Estonia, Finland, France and Germany). The data of five years from 2014-2018 has been presented and used for calculations. Using TOPSIS method of MCDM, it can be found that which country is best to trade with. From the results of examination, it very well may be seen that Denmark stands first, Finland stands second, Germany stands third, Austria stands fourth, Estonia stands fifth, France stands 6th, Belgium stands seventh and Chech Republic stands eight according to Internet access and utilization by Individuals. The results shows that Denmark is the best country to trade with as it has the maximum number of Individuals accessing and using internet and Check Republic is the worst country to trade to trade with as it has the least number of Individuals accessing and using Internet which would result in less communication.

\section{References}

Apostolov, M. (2008). Good governance and the concept of electronic single window for international trade. In ICEGOV '08 Proceedings of the $2^{\text {nd }}$ International Conference on Theory and Practice of Electronic Governance (pp. 8-9). https://doi.org/10.1145/1509096.1509100

Blagodurov, S., Fedorova, A., \& Evgeny, E. (2015). Multi-Objective Placement in clusters. In SC'15 Proceedings of the International Conference for High Performance Computing, Networking, Storage and Analysis (Article No.: 66, pp. 112). https://doi.org/10.1145/2807591.2807636

Blumenstock, J. E.(2005). Using mbile phone data to measure the ties between nations. In iConference'11 Proceedings of the 2011 Iconference (pp. 195-202). https://doi.org/10.1145/1940761.1940788

Chen, Y., Chen, M., \& Faulkner, G. (2005). Towards a conceptual design of an intelligent system for an international trade centre in China. In ICEC '05 Proceedings of the $7^{\text {th }}$ International Conference on Electronic Commerce (pp. 78-84). https://doi.org/10.1145/1089551.1089570

Cikic, S., Grottke, S., Lehmann-Grube, F., \& Sablatnig, J. (2008). Cheat-prevention and -analysis in online virtual worlds. In e-Forensics'08 Proceedings of the $1^{\text {st }}$ International Conference on Forensic Applications and Techniques in Telecommunications, Information, and Multimedia and Workshop (Article No. 13). https://doi.org/10.4108/e-forensics.2008.2650

Clausen, L., Zolner, M., Soderberg, A.-M., \& Worm, V. (2009). Cultural intelligence as a strategic ressource in multicultural teams. In IWIC '09 Proceedings of the 2009 International Workshop on Intercultural Collaboration (pp. 211-214). https://doi.org/10.1145/1499224.1499258

Daily, B. F., Loveland, J., \& Steiner, R. (1997). A comparative analysis of reactions from multicultural and culturally homogeneous teams to decision making with and without GDSS technology. Computer Personnel, 18(1), 3-14. https://doi.org/10.1145/270553.270554

Debenham, J., \& Simoff, S. (2009). Believable electronic trading environments on the Web. In Proceedings of the 2009 IEEE/WIC/ACM International Joint Conference on Web Intelligence and Intelligent Agent Technology (Vol. 01, pp. 631-638). https://doi.org/10.1109/WI-IAT.2009.106

Dhar, V. (2015). Should you trust your money to a robot? In KDD'15 Proceedings of the $21^{\text {th }}$ ACM SIGKDD International Conference on Knowledge Discovery and Data Mining (pp. 1625-1626). https://doi.org/10.1145/2783258.2790455

Faltaous, S., Elbolock, A., \& Talaat, M. (2018). Virtual reality for cultural competences. In MUM 2018 Proceedings of the $17^{\text {th }}$ International Conference on Mobile and Ubiquitous Multimedia (pp. 457-461). https://doi.org/10.1145/3282894.3289739

Fischlmayr, I. (2012). Bridging cultures via an online business simulation over different time zones. In ICIC '12 Proceedings of the $4^{\text {th }}$ International Conference on Intercultural Collaboration (pp. 31-38). https://doi.org/10.1145/2160881.2160887

Gabriel, H. D. (2003). The emerging law of international electronic commerce: Recent work by UNCITRAL. In ICEC '03 Proceedings of the $5^{\text {th }}$ International Conference on Electronic Commerce (pp. 367-375). https://doi.org/10.1145/948005.948052

Gordijn, V. K. J., \& Tan, Y.-H. (2004). Analysing preventative and detective control mechanisms in international trade using value modelling. In ICEC '04 Proceedings of the $6^{\text {th }}$ International Conference on Electronic Commerce (pp. 51-58).

Husby, P. G. (1984). International market opportunities (Panel). In SIGGRAPH '84 Proceedings of the $11^{\text {th }}$ Annual Conference on Computer Graphics and Interactive Techniques (p. 117). https://doi.org/10.1145/800031.808587

Lewis, S., B., Ellis, J., \& Kellogg, W. A. (2010). Using virtual interactions to explore leadership and collaboration in globally distributed teams. In ICIC '10 Proceedings of the $3^{\text {rd }}$ International Conference on Intercultural Collaboration (pp. 918). https://doi.org/10.1145/1841853.1841856

Li, Y., Li, H., \& Madche, A. (2012). Are you a trustworthy partner in a cross-cultural virtual environment? : Behavioral cultural intelligence and receptivity-based trust in virtual collaboration. In ICIC '12 Proceedings of the $4^{\text {th }}$ International Conference on Intercultural Collaboration (pp. 87-96). https://doi.org/10.1145/2160881.2160895

Lisak, A., \& Erez, M. (2009). Leaders and followers in multi-cultural teams: their effects on team communication, team identity and team effectiveness. In IWIC '09 Proceedings of the 2009 International Workshop on Intercultural Collaboration (pp. 81-88). https://doi.org/10.1145/1499224.1499238 
Liu, S. (2005). Electronic Trading (ET): New method in finance markets. In ICEC'05 Prceedings of the $7^{\text {th }}$ International Conference on Electronic Commerce (pp. 900-903). https://doi.org/10.1145/1089551.1089729

Luo, W., MacEachren, S., \& Zwaenepoel, W. (2011). Saptial-Social network visualization for exploratory data analysis. In LBSN '11 Proceedings of the $3^{\text {rd }}$ ACM SIGSPATIAL International Workshop on Location-Based Social Networks (pp. 65-68). https://doi.org/10.1145/2063212.2063216

Massey, P. A., Hung, Y.-T. C., \& Ramesh, V. (2011). When culture and style aren't about clothes: Perceptions of tasktechnology "fit" in global virtual teams. In GROUP '01 Proceedings of the 2001 International ACM SIGGROUP Conference on Supporting Group Work (pp. 207-213). https://doi.org/10.1145/500286.500318

Mattos, D. M. F., Ferraz, L. H. G., Costa, L. H. M. K., \& Duarte, O. C. M. B. (2012). Evaluating virtual router performance for a pluralist future internet. In ICICS '12 Proceedings of the $3^{\text {rd }}$ International Conference on Information and Communication Systems (Article No. 4, pp. 1-7). https://doi.org/10.1145/2222444.2222448

Menon, A., Schubert, S., \& Zwaenepoel, W. (2009) TwinDrivers: Semi-automatic derivation of fast and safe hypervisor network drivers from guest OS drivers. In ASPLOS XIV Proceedings of the $14^{\text {th }}$ International Conference on Architectural Support for Programming Languages and Operating Systems (pp. 301-312). https://doi.org/10.1145/1508244.1508279

Noll, J., Beecham, S., \& Richardson, I. (2011). Global software development and collaboration: barriers and solutions. In ACM Inroads Archive, 1(3), 66-78. https://doi.org/10.1145/1835428.1835445

O‘Leary, D. E. (1998). Virtual organiztaion: Two choice problems. In ICIS '98 Proceedings of the International Conference on Information Systems (pp. 145-154).

OECD. (2019). ICT access and usage by households and individuals: ICT access and usage by individuals. https://stats.oecd.org

Oh, J. S., Kwon, J. W., Park, H., \& Moon, S. M. (2015). Migration of Web Applications with Seamless Execution. In VEE '15 Proceedings of the $11^{\text {th }}$ ACM SIGPLAN/SIGOPS, International Conference on Virtual Execution Environments (pp. 173-185). https://doi.org/10.1145/2731186.2731197

Parra, C. T. D., \& Wen, L. E. X. (2014). Who will trade with whom?: Predicting buyer-seller interactions in online trading platforms through social networks. In WWW'14 Companion Proceedings of the $23^{\text {rd }}$ International Conference on World Wide Web (pp. 387-388). https://doi.org/10.1145/2567948.2577364

Powell, A., Piccoli, G., \& Ives, B. (2004). Virtual teams: A review of current literature and directions for future research. In ACM SIGMIS Database: The DATABASE for Advances in Information Systems, 35(1), 6-36. https://doi.org/10.1145/968464.968467

Rashid, A. (2010). Using a service oriented architecture for simulating algorithmic trading strategies. In iiWAS '10 Proceedings of the $12^{\text {th }}$ International Conference on Information Integration and Web-based Applications \& Services (pp. 925-929). https://doi.org/10.1145/1967486.1967650

Redmiles, D., Prikladnicki, R., Marczak, S., \& Calefato, F. (2013). Trust in virtual teams: theory and tools. In CSCW '13 Proceedings of the 2013 Conference on Computer Supported Cooperative Work Companion (pp. 301-306).

Robert, L. P. (2013). A multi-level analysis of the impact of shared leadership in diverse virtual teams. In CSCW' 13 Proceedings of the 2013 Conference on Computer Supported Corporative Work (pp. 363-374). https://doi.org/10.1145/2441776.2441818 